\title{
Contribution to the Definition and Modeling of Service and Service Activities
}

\author{
Mounir Badja, Wael Touzi, and Thècle Alix \\ IMS, University of Bordeaux, CNRS, 351 Cours de la Libération, \\ 33405 Talence Cedex, France \\ Tel.: +33 (5) 4000 6532; Fax: +33 (5) 40006644 \\ \{Mounir.Badja, Wael. Touzi, Thécle.Alix\}@ims-bordeaux.fr
}

\begin{abstract}
For a long time, it was highlighted that the service is intangible or immaterial; these characteristics are mainly used to distinguish the service, making it incomparable with good. The set of proposed definitions and characteristics that led to debates between specialists in economics for several years and gave place to a variety of visions and approaches are still not consensual and science engineers challenge. Goal of this paper is to present, on the one hand, the existing literature proposed by economists concerning services (definitions and specificities) and, on the other, arguments proposed by science engineers that challenge them. That study allows us to propose a generic definition of what a service is and a preliminary model of a service activity.
\end{abstract}

Keywords: Service characteristics, Service modeling, Process modeling.

\section{Introduction}

Services have been recently powerful engines of economic growth in many economies with such sign that today, a developed economy, would be a "tertiarized" economy [1]. Economists, Marketers, Human Resource Managers have studied the service economy, service marketing and service relation for a long time [2], [3], [4]. All have proposed definitions, associated different characteristics and defined specific tools for management.

Now that services represent a way to innovate in any sector of activity and since they have spread, particularly in the manufacturing area to differentiate from competitors and offer advantages, it becomes obvious to increase service efficiency and to cross disciplinary efforts to enrich services research [5]:

- Academics belonging to the manufacturing community are interested in investigating this sector and propose methods and tools to help modeling and controlling firms that are redeployed in product-service systems.

- Industrialists, for their concern, aims at developing coherent tools to manage efficiently service offers and service innovations that are synonyms of profitability and customers' loyalty.

Defined by these latest in a rather negative sense and considered as residual, dependent on manufacturing, technologically backward and not very innovative for a long time, services activities and services in general receive now a better echo. Studies led concern service delivery systems analysis, service operation management, 
business process modeling, service quality evaluation and performance measurement, service value, service engineering, etc. and meet the studies already performed.

All these investigations that are necessary to deliver high value to the customer and to reach firms' objectives in terms of profitability and durability rest on the understanding of what a service is conceptually and on the analysis of the differences and similarities between products and services to help manufacturers understand what is specific to service delivery and what might be adapted. On the basis of a literature review presented in the following part and, on a qualitative survey presented in the third part of this paper, a definition and modeling principles are proposed in the fourth part before concluding.

\section{Definitions and Characteristics of Services in the Literature Review}

\subsection{Service Definitions}

A general consensus exists regarding the definition and execution of industrial production activities; it is less certain for the questions related to services, service activities and service execution. This is mainly due to the structural change of the service sector and to the historical tradition to consider services as a homogenous residual of a more "productive" manufacturing. Indeed, service is a complex and subjective matter, which allows individual interpretation and perception.

Nevertheless, it is useful to present some literature definitions to structure our approach and to better define the different characteristics of services that will be used thereafter for the model. The ones that are proposed here are the most cited in the literature:

- "A service may be defined as a change in the condition of a person, or of a good belonging to some economic unit, which is brought about as the result of the activity of some other economic unit, with the prior agreement of the former person or economic unit" [6].

- "Service is a transformation of existence mode and/or dispositions of the person himself, of his body and his mind. While goods modify the existence conditions, services modify the existence modes, where goods are only supports" [7].

- "A service is an act (or a succession of acts) of duration and localization defined, achieved thanks to human and/or material means, implemented for the benefit of an individual or collective customer, according to processes, codified procedures and behaviors" [8].

These definitions have in common the notion of activity or process, the notion of time and the concept of interaction between a supplier and a customer. They all gather characteristics that led to the definition of specific tools and methods of analysis and management.

\subsection{Characteristics of Services}

Researchers started to enumerate distinctive characteristics of services in order to distinguish them from goods [9] [10] [11]:

- A service is not owned, but there is a restricted access.

- Services have intangible results. 
- Customers are involved in the service production process.

- Other persons than the customer can be involved in the service process.

- Quality in service is difficult to control while increasing productivity.

- Quality in service is difficult to apprehend.

- Service cannot be stored.

- Service delivery delay is crucial.

- Service delivery integrates physical and electronic way.

Based on these assertions, four characteristics named IHIP characteristics (i.e. Intangibility, Heterogeneity, Inseparability and Perishability characteristics) have merged to exemplify a service.

As related by the management literature, there are also some key characteristics that are common of all service activities. The main features of the service activity stems from the specific role played by the customer source of other attributes such as a co-production with the firm contact personnel and an uncertainty concerning the service outcome link to the conditions of the interpersonal exchange [6].

\section{Qualitative Survey}

A new community coming from the engineering science is investigating the service domain. In order to cross the points of view and enrich our understanding on services, a survey was carried out by the way of several interviews of engineers. Performed in facing each other, they focused on three main themes: an individual definition of services and associated characteristics, an analysis of the link existing between a product and a service and finally a comparison of the key elements to manage to produce a product and a service or more specifically a comparison between the model of production of a product and the "servuction" model.

\subsection{Presentation of the Qualitative Survey}

About eleven engineers were questioned during the survey carried out by two persons in the following way: a document presenting the results of the literature review was performed and sent to the interviewed persons by e-mail. Appointments were taken and conversations on the above-mentioned themes were recorded.

\subsection{Processing and Analysis of Interviews}

During the interviews, each interviewee expressed his own opinion on a service definition. Gathering and analysing these definitions, we have noted some key elements:

- The service is an answer to a need,

- The human factor impacts the production of the service,

- The service process impacts its outputs as well as all the elements which play a role during its execution,

- An ontology of service might be defined because of the multiplicity of terms used and underlying concepts.

Concerning the characteristic of inseparability and perishability, there was a total convergence of views. Interviewees were also in agreement with the fact that a ser- 
vice is produced at the same time it is consumed. Concerning the intangibility and heterogeneity characteristics, the points of view diverge.

Indeed, regarding the intangible nature of service (in the sense of impalpable), $80 \%$ of respondents supports this hypothesis but affirm that the value and effect of service is tangible and that the service should be supported by substantial resources.

Regarding the heterogeneity of services, opinions are more divided. $20 \%$ think that service is homogenous and $30 \%$ of respondents have a shared view on the subject. Note that, here, heterogeneity is defined by the fact that "... a same service has a different result according to the person who provides it, the customer who receives it and the moment when this exchange is done" [12]. This difference in opinion stems from the fact that some think that service is heterogeneous with a generic base, and also depend from a deference between customer view (perceived service) and supplier view (delivered service).

Regarding the characteristic of storability, although opinions are divided, the majority thinks that service is non-storable due to the impossibility of their storage (the service being an interaction between customer and provider). Some others think that a service is storable and affirm that it can be viewed as a sort of pass for press.

For perishability, the concept of time could be a common discriminator between a product and a service as a service might meet a need during a limited time (e.g. transport).

The observed divergences and the interviewee responses depend narrowly on their initial service definitions and their research topic. The gathering of definition and points of views allow us to propose our definition of services taking account of the duality between goods and services.

\section{Service Definition Proposition}

The definition proposal is not an aim in itself, but is an essential step without which we cannot claim to seriously work on service. Based on the previous literature review and the results of the survey interpretations, we propose to define the service as the execution or the instantiation of an activity generating, an artifact and/or a state change of the artifact or the input agent, consuming entities (capacity to serve) grouped in resources, inputs and controls; attempting to satisfy customer needs.

To make explicit the proposed definition, it is necessary to define the meaning of each term that is used and illustrate the definition using some conceptual diagrams.

We define the service as an execution activity, without taking account of the activity output nature (material/immaterial) and without distinguish the service provider from the service customer (self-service/customer-provider). From an operational and modeling point of view the execution activity can be seen as the instantiation of an activity done by affecting a value to the activity, resources, inputs, controls and outputs.

\subsection{Service Meta-model}

We assume that the service consumes and produces entities classified as artifacts or agents (Fig.1). "An artifact may be defined as an object that has been intentionally made or produced for a certain purpose" [13][14]. The artifact intentionality is a fundamental element [15], thus natural entity become artifact by attributing an intentionality (a pebble used like a paperweight is an artifact). We distinguish physical and 
no physical artifacts [16], where the firsts are the only ones having direct spatial dimensions and functions, these functions provide no physical artifacts. An agent is an entity having the capacity to accomplish actions using some competency and to provide no physical artifacts [16].

These entities take part in a service as an inputs, outputs, resources and controls. The entity serve capacity depends on its capability to provide no physical artifacts (broken car has no transport serve capacity), the entity with low serve capacity needs to consume a service to increase this capacity and be able to participate in the supported service (broken car needs mechanical repair service to be able to perform transport).

According to serve capacity possible values, we can define several entity states; the transition between two entity states can be induced by consuming service or by participating to service providing. The serve capacity evolution of service participating entities depends on the entity nature (a software developer increases his competency and developing serve capacity when he participates to development service) (a knife deceases its cutting serve capacity when it's used in a service).

If we assume that in our view the entity is not all the time participating in service, then the transition between two entity states can also be induced by other factors such as events or the time.

The service consumption responds to entity need, artifact need is different from agent need. The artifact need is closely linked to its serve capacities and needs services to be able to provide other services. An artifact with no functions will certainly disappear. The agent need for its concern includes two views: the first one is similar to the artifact need i.e. where the agent consumes services to provide other ones (a machine operator needs to consume formation service to provide a service on a specific machine). The second view is to consider the intrinsic human needs, which "... arrange themselves in hierarchies of pre-potency..." where "... the appearance of one need usually rests on the prior satisfaction of another ...” [17].

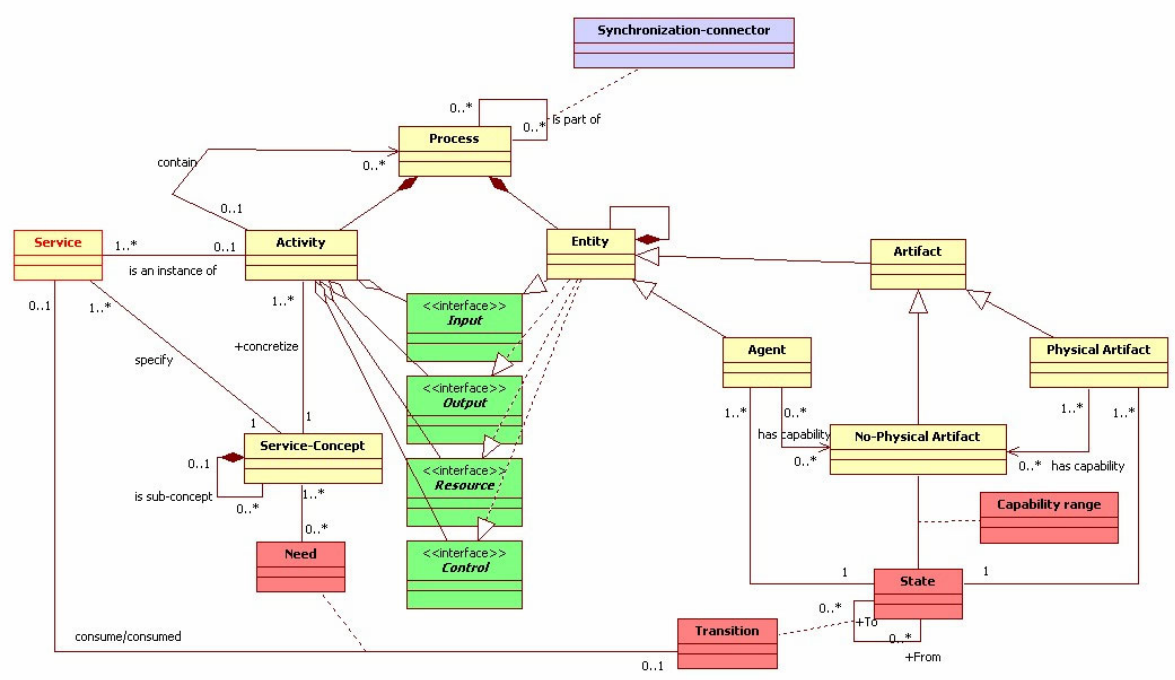

Fig. 1. Proposed service meta-model 


\subsection{Service Modeling}

We gather considered concepts using UML class diagram (Fig. 1) [18] within which three class groups coexist, representing three views: (i) the functional view (Service, Activity, Entity, Process and Service-Concept), (ii) the interaction view (Service, State, Transition, Need and Entity) and (iii) the dynamic view (Activity, Entity, Process and Synchronization-connector).

The functional view allows to model the service, its inputs, its outputs and its activity using a mix of IDEF0, IEM [19] languages and integrating UML instantiation notion (Fig. 2). The activity represents a proposed response for the service-concept gathering customer needs, and the service an instantiation of this response.

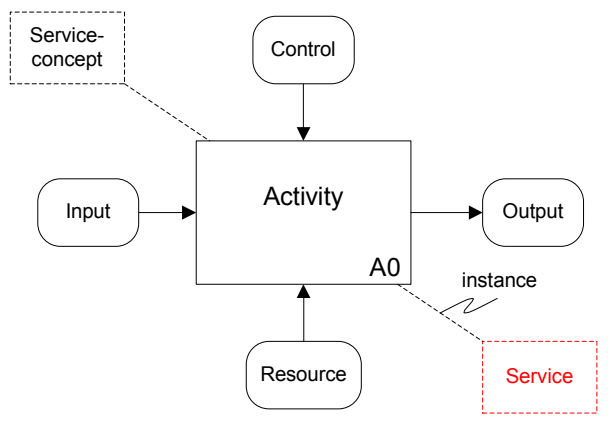

Fig. 2. Service functional view

Based on the UML state machine diagrams [18], the interaction view allows modeling the entities states and the transitions between them (fig. 3). The service here consumes serve capacities (and/or entities) inducing entity state change (and/or producing entities) according to the need.

The dynamic view allows to describe the sequences that are mandatory to execute the service. This view is based on BPMN [20].

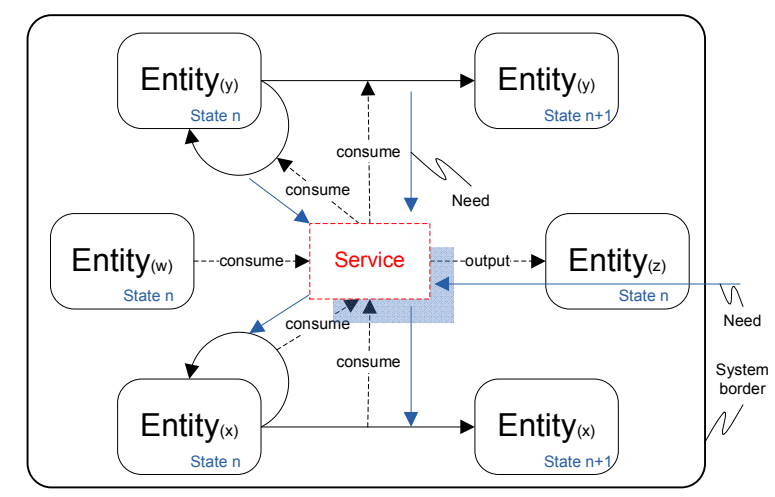

Fig. 3. Service interaction view 


\subsection{The Definition Proposal and the IHIP}

After having proposed a definition and a modeling of the service, we check the IHIP characteristics and there link with the proposed point of view. The service defined as an execution activity is:

- Intangible; the execution being an order of actions, it is immaterial but can act on physical or no physical entities.

- Heterogeneous; the service being an activity instantiation each instance is different, with a common base (activity description).

- Inseparable; the execution gathers the provider and the customer during the execution duration (self-service/customer-provider).

- Perishable; the execution taking a finite time, the service only exists during its execution.

\section{Conclusion}

In the current economic context, the problem of service becomes a key issue. This article points both the contributions of the economic literature and the recent developments in service theory. We have proposed a definition and a service model that takes into account the service nature and characteristics and the links service/resources, which are considered as serve capability container. This view of service allows a better action on service.

Various questions suggest new fields of investigation, and future pathways of research to the evaluation of performance in services, study the quality of services, the definition of a production typology for material product and/or immaterial product, the formalization of public services, and new typology of services.

\section{References}

1. Edvardson, B., Gustafsson, A., Roos, I.: Service portraits in service research: a critical review. International journal of service industry management 16(1), 107-121 (2005)

2. Berry, L.L.: Relationship marketing of services - growing interest, emerging perspectives. Journal of the Academy of Marketing Science 23(4), 236-245 (1995)

3. Fisk, R.P., Grove, S.J., John, J.: Services Marketing Self-Portraits: Introspections, Reflections, and Glimpses from the Experts. American Marketing Association, Chicago (2000)

4. Zeithaml, V.A., Berry, L.L., Parasuraman, A.: The behavioral consequences of service quality. Journal of Marketing 60, 31-46 (1996)

5. Wild, P.J., Clarkson, P.J., McFarlane, D.C.: A framework for Cross Disciplinary Efforts in Services Research. In: CIRP IPS2 Conference, Cranfield, UK, April 1-2 (2009)

6. Hill, T.P.: On Goods and Services. Review of Income and Wealth, series 23(4) (1977)

7. Zarifian, P.: Evénement et sens donné au travail',In, coordonné par Gilles Jeannot et Pierre Veltz, 'Le travail, entre l'entreprise et la cite, éditions de l'Aube, pp. 109-124 (2001)

8. Dumoulin, C., Flipo, J.P., et al.: Entreprise de service: 7 facteurs clés de success, les editions d'organisation, p. 211 (1991)

9. Lovelock, C., Wirtz, J., Lapert, D.: Marketing des services, p. 620. Pearson Education, London (2004) 
10. Touzi, W., Alix, T., Vallespir, B.: An investigation into service and product characteristics to expand innovation. In: ERIMA 2008 Conference, Porto, Portugal, November 6-7 (2008)

11. Alix, T., Vallespir, B.: Gathering production Process of services and goods: towards the mixed enterprise. In: APMS 2006, IFIP. lean business systems and beyond, vol. 257, pp. 317-325 (2006)

12. Eiglier, P., Langeard, E.: Servuction: Le Marketing des Services. McGraw-Hill, Paris (1987)

13. Baker, L.R.: The Ontology of Artifacts. Philosophical Explorations. An International Journal for the Philosophy of Mind and Action 7, 1741-5918, 99-111 (2004)

14. Hilpinen, R.: Artifact: Stanford Encyclopedia of Philosophy, http: //plato.stanford.edu/entries/artifact/

15. Vieu, L., Borgo, S., Masolo, C.: Artefacts and Roles: Modelling Strategies in a Multiplicative Ontology. In: Proceedings of the Fifth International Conference, FOIS, pp. 121-134. Saarbrücken, Germany (2008)

16. Kassel, G.: Vers une ontologie formelle des artefacts.: 20es Journées Francophones en Ingénierie des Connaissances, Tunisie (2009)

17. Maslow, A.H.: A Theory of Human Motivation. Psychological Rev., 370-396 (1943)

18. Fowler, M.: UML Distilled: A Brief Guide to the Standard Object Modeling Language, 3rd edn. Addison Wesley, Reading (2003)

19. Spur, G., Mertins, K., Jochem, R.: Integrated Enterprise Modelling, Berlin, Wien, Zürich Berlin (1996)

20. OMG: Business Process Modeling Notation (BPMN), Version 1.0, OMG Final Adopted Specification. Object Management Group (2006) 